\title{
A simultaneous observation of lightning by ASIM, ColombiaLightning Mapping Array, GLM and ISSLIS
}

Montanyà, Joan; López, Jesús A.; Morales Rodriguez, Carlos A.; van der Velde, Oscar A.; Fabró, Ferran; Pineda, Nicolau; NavarroGonzález, Javier; Reglero, Víctor; Neubert, Torsten; Chanrion, Olivier

Total number of authors:

17

Published in:

Journal of Geophysical Research: Atmospheres

Link to article, DOI:

10.1029/2020JD033735

Publication date:

2021

Document Version

Publisher's PDF, also known as Version of record

Link back to DTU Orbit

Citation (APA):

Montanyà, J., López, J. A., Morales Rodriguez, C. A., van der Velde, O. A., Fabró, F., Pineda, N., Navarro González, J., Reglero, V., Neubert, T., Chanrion, O., Goodman, S. J., Østgaard, N., LadinoRincon, A., Romero, D., Solà, G., Horta, R., \& Freijó, M. (2021). A simultaneous observation of lightning by ASIM, ColombiaLightning Mapping Array, GLM and ISSLIS. Journal of Geophysical Research: Atmospheres, 126(6).

https://doi.org/10.1029/2020JD033735

\section{General rights}

Copyright and moral rights for the publications made accessible in the public portal are retained by the authors and/or other copyright owners and it is a condition of accessing publications that users recognise and abide by the legal requirements associated with these rights.

- Users may download and print one copy of any publication from the public portal for the purpose of private study or research.

- You may not further distribute the material or use it for any profit-making activity or commercial gain

- You may freely distribute the URL identifying the publication in the public portal 


\title{
A simultaneous observation of lightning by ASIM, Colombia-Lightning Mapping Array, GLM and ISS-LIS
}

\author{
Joan Montanyà ${ }^{1}$, Jesús A. López ${ }^{1}$, Carlos A. Morales Rodriguez², Oscar A. \\ van der Velde ${ }^{1}$, Ferran Fabró ${ }^{3,1}$, Nicolau Pineda ${ }^{3,1}$, Javier Navarro- \\ González $^{4}$, Víctor Reglero ${ }^{4}$, Torsten Neubert ${ }^{5}$, Olivier Chanrion ${ }^{5}$, Steven J. \\ Goodman $^{6}$, Nikolai Østgaard ${ }^{7}$, Alfonso Ladino-Rincon ${ }^{8}$, David Romero ${ }^{1}$, \\ Glòria Solà ${ }^{1}$, Ricard Horta ${ }^{1}$ and Modesto Freijó ${ }^{1}$
}

1. Lightning Research Group, Dept. of Electrical Engineering, Polytechnic University of Catalonia (UPC), Colom 1, 08222 Terrassa (Barcelona), Spain

2. Departamento de Ciências Atmosféricas, Instituto de Astronomia, Geofísica e Ciências Atmosféricas, Universidade de São Paulo, São Paulo, Brazil

3. Meteorological Service of Catalonia, Barcelona, Spain

4. Image Processing Laboratory, University of Valencia, Valencia, Spain

5. National Space Institute, Technical University of Denmark, (DTU-Space), Elektrovej Bld. 328, 2800 Kgs. Lyngby, Denmark

6. Thunderbolt Global Analytics, Owens Cross Roads, AL USA

7. Birkeland Centre for Space Science, Dept. of Physics and Technology, University of Bergen, Bergen, Norway

8. Department of Atmospheric Sciences, University of Illinois, Urbana, IL USA

Key points:

1. Features of luminosity from a lightning flash detected by ASIM, GLM and LIS are related with leader development and cloud properties.

2. Surges in $777.4 \mathrm{~nm}$ luminosity are associated with return stroke currents, continuing currents, recoil leaders and leader branching.

3. Altitude of lightning leaders, cloud particles above lightning channels as well as channel luminosity influence the detection of light.

This article has been accepted for publication and undergone full peer review but has not been through the copyediting, typesetting, pagination and proofreading process, which may lead to differences between this version and the Version of Record. Please cite this article as doi: 10.1029/2020JD033735. 


\section{Abstract}

The Atmosphere-Space Interactions Monitor (ASIM) on the International Space Station (ISS) provides optical radiances and images of lightning flashes in several spectral bands. This work presents a lightning flash simultaneously observed from space by ASIM, the Geostationary Lightning Mapper (GLM) and the Lightning Imaging Sensor on the International Space Station (ISS-LIS); and from ground by the Colombia Lightning Mapping Array (Colombia-LMA). Volumetric weather radar provides reflectivity data to help to interpret the effects of the cloud particles on the observed optical features. We found that surges in radiance in the band at $777.4 \mathrm{~nm}$ appear to be related mostly with lightning processes involving currents as well with branching of lightning leaders with new leader development. In cloud areas with reflectivity $<18 \mathrm{dBZ}$ above the lightning leader channels at altitudes $>7 \mathrm{~km}$, these have been imaged by ASIM and GLM. But in the region with reflectivity $<23 \mathrm{dBZ}$, despite its lower cloud tops and similar altitudes of lightning channels, these have been almost undetectable. The calculated relative optical depths are consistent with the observed optical intensity at the cloud top. Despite the effects of the cloud particles and the altitude of the lightning channels on the attenuation of the luminosity, the luminosity of the lightning channels due to different processes is fundamental for the imaging of lightning from space.

\section{Introduction}

In the near future, much of the Earth's lightning activity will be continuously monitored from space by lightning imagers placed in geostationary orbit. These new satellite-based instruments open a new era of weather monitoring and research into the role of thunderstorm processes in the dynamics of the atmosphere and in climate change. The Geostationary Lightning Mapper (GLM) on the first of the Geostationary Operational Environmental Satellite GOES $\square$ R Series (GOES-16 at 75.2W) is the first lightning detector in geostationary orbit (Goodman et al., 2013; Rudlosky et al., 2019ab). GLM is based on its predecessors, the Optical Transient Detector (OTD) and Lightning Imaging Sensor (LIS) (Christian et al., 1989). In China, the Lightning Mapping Imager (LMI) on the Feng-Yun4 is detecting lightning in Asia (Yang et al., 2017) and in the near future, Europe and Africa will be continuously monitored by the Lightning Imager (LI) on the 
Meteosat Third Generation satellites (MTG) (Stuhlmann et al., 2005). All of these systems, new to the geostationary orbit, use optical imagers at the narrow spectral line at the $777.4 \mathrm{~nm}$ infrared emission of atomic oxygen that is associated with hot lightning channels (e.g. Soler et al., 2020).

The Atmosphere-Space Interactions Monitor (ASIM) on the International Space Station (ISS) consists of a suite of optical instruments and X-and gamma-ray detectors for investigating lightning, Transient Luminous Events (TLEs) and Terrestrial Gamma-ray Flashes (TGFs) (e.g. Chanrion et al., 2019; Neubert et al., 2019). ASIM is equipped with three photometers at $180-230 \mathrm{~nm}, 337.0 \mathrm{~nm}$ and $777.4 \mathrm{~nm}$ spectral bands plus two onemegapixel cameras at $337.0 \mathrm{~nm}$ and $777.4 \mathrm{~nm}$. The objective of the $337.0 \mathrm{~nm}$ (blue) and $777.4 \mathrm{~nm}$ (red) instruments is to quantify optical energy leaving from the top of the clouds and to provide images of lightning events. The selected red $(777.4 \mathrm{~nm})$ band monitors the emission from neutral atomic oxygen caused by lightning processes like the return stroke and recoil leader events (e.g. Thomas et al., 2000) whereas the blue (337.0 nm) emissions are characteristic of the $\mathrm{N}_{2} 2^{\text {nd }}$ positive system (SPS) which are common in electrical discharges but have been little investigated in lightning. Recently, Soler et al. (2020) have shown blue optical emissions with absence of red to be related with narrow-bipolar events. In these cases, the blue emission is considered to be produced by cold electrical discharges like streamers. In addition to the red and blue channels, the selected far UV (180-230 nm) channel allows the discrimination of TLEs in the higher atmosphere since the optical emissions in this band coming from the troposphere (e.g. from lightning) would be highly attenuated. Because ASIM instruments provide high temporal and spatial resolution of optical activity in the clouds with additional spectral bands. ASIM offers an opportunity to explore in more detail the performance of the lightning imagers in geostationary orbit (e.g. van der Velde et al., 2020). The comparison of data from ASIM in the low-Earth-orbit of the ISS ( $400 \mathrm{~km}, 51.6^{\circ}$ inclination) to the geostationary instruments is facilitated by a LIS instrument, also on the ISS (Blakeslee et al., 2020).

The optical emission from lightning that escapes from a cloud is highly affected by scattering and absorption of photons by cloud particles which reduce the signal intensity, and broadens emissions in space and time (e.g. Thomason and Krider, 1982; Peterson, 2019; Thomason and Krider, 1982; Koshak et al., 1994; Light et al., 2001; Peterson, 2014; Luque et al., 2020; Brunner and Bitzer, 2020). This effect has been the subject of several studies that compare detection from space with data from lightning detection systems at

This article is protected by copyright. All rights reserved. 
ground. In particular, the measurements of Lightning Mapping Array (LMA) networks (Rison et al., 1999) have been useful because they provide 3D reconstructions of lightning leader development inside the clouds. The early comparisons between LIS and LMA (Thomas et al., 2000) showed that most of the detected optical events were associated with lightning channels at the upper part of the storms. Cloud-to-ground (CG) flashes confined to mid and lower altitudes were less detected. In addition, the strongest light emissions were identified to be related with impulsive high current events from recoil leader activity. Most of the works comparing space-based optical detections and LMA flash data focused on the evaluation of the detection efficiency (e.g. Montanyà et al. 2019; Erdmann et al., 2020; Zhang and Cummins, 2020). In these works, only lightning is considered but not the microphysical characteristics of the clouds in which lightning flashes are immersed and their effect on to the propagation of light. Recently, Rutledge et al. (2020) has incorporated radar and LMA data to evaluate GLM. In this work it has been identified that GLM detection efficiency depends on the lightning flash geometric size, in agreement with Zhang and Cummins (2020), and the cloud water path. The size of the flash was found to be correlated with the optical brightness whereas the cloud water path was related to the optical extinction. The cloud water path, in turn, depends on the height of the flash that was derived from LMA clustered data and the cloud water content. Using radar, the mean precipitation-sized hydrometeor ice water paths were determined but, with S-band radars, cloud particles cannot be detected. The authors pointed out that despite the small surface areas of cloud particles compared to precipitation-sized ones, their greater concentrations can provide more attenuation of optical energy. In the present work we complement the previously introduced works by relating lightning processes and cloud properties in a LMA flash case observed with the high resolution ASIM photometers and cameras.

This study presents the first report of a lightning flash occurring in a location with simultaneous coverage by the optical photometers and cameras of ASIM, the ColombiaLMA, the GOES-16 Advanced Baseline Imager (ABI), weather radar data, the GLM and the ISS-LIS. The flash occurred on November 22, 2018 at 08:57:21.4413 UT. We analyze the measurements of the ASIM, GLM and ISS-LIS instruments relative to the lightning propagation detected by the LMA and the influence of cloud properties estimated from weather radar data. The object of the analysis is to identify the relation of the red and blue

This article is protected by copyright. All rights reserved. 
optical emissions with different lightning processes and the effects of the cloud properties on the measured luminosity.

\section{Data}

As ground support for the ASIM mission, the group at the Polytechnic University of Catalonia (UPC) installed one LMA in the Ebro river delta in North-Eastern Spain and another in Colombia (van der Velde and Montanyà, 2013; López et al., 2019). At the time of the event, the Colombia-LMA was composed of 6 stations close to the city of Barrancabermeja $\left(\sim 7^{\circ} \mathrm{N}, 73.85^{\circ} \mathrm{W}\right)$ in Colombia. The LMA system detects sources of radio emissions in the very high frequency range (VHF, 30-300 MHz) that originate from the breakdown processes related to the propagation of lightning leaders. The sources are located in three dimensions using the time-of-arrival technique. Detailed information about the LMA can be found in Rison et al. (1999) and Thomas et al. (2004).

The Modular Multispectral Imaging Array (MMIA) optical sensors of ASIM are three photometers at 180-230 nm (UV), $337.0 \mathrm{~nm}$ (4 nm bandwidth) (hereafter the blue signal) and $777.4 \mathrm{~nm}(5 \mathrm{~nm}$ bandwidth) (hereafter the red signal) at 10 microsecond resolution, and two cameras with 1000 x1000 pixels and 12 frames per second at $337.0 \mathrm{~nm}(5 \mathrm{~nm}$ bandwidth) and $777.4 \mathrm{~nm}$ ( $3 \mathrm{~nm}$ bandwidth). The angle of view of the blue and red photometers is $80^{\circ}$ with a square sensor. The UV photometer has a circular sensor with an angle of view of $80^{\circ}$. The spatial resolution of the cameras is $\sim 400 \mathrm{~m}$ per pixel towards nadir. A more detailed description of the instruments is found in Chanrion et al. (2019) and in van der Velde et al. (2020).

The Geostationary Lightning Mapper (GLM) and the Lightning Imaging Sensor (ISSLIS) provide locations of the sources (events) of luminosity for the investigated lightning flash with $2 \mathrm{~ms}$ resolution (GOES-R Algorithm Working Group and GOES-R Series Program, 2018). The minimum pixel footprints of GLM and ISS-LIS imagers are $8 \mathrm{~km}$ and $4 \mathrm{~km}$, respectively. Radiance at the measured $777.4 \mathrm{~nm}$ narrow band for each event is provided.

This article is protected by copyright. All rights reserved. 
Cloud-to-ground (CG) lightning locations and peak currents are provided by the Keraunos SAS LINET type lightning network in Colombia (Betz et al., 2009; Aranguren et al., 2017) and by the World-Wide Lightning Location Network (WWLLN, e.g. Rodger et al., 2006). Additionally, extremely low frequency (ELF) magnetic fields $(<0.01$ to 300 $\mathrm{Hz}$ ) measured by the UPC Schumann resonance station in Cape Verde $\left(16.73^{\circ} \mathrm{N}\right.$, $22.93^{\circ} \mathrm{W}$ ) are used to identify the presence of continuing currents for those transient events superimposed over the continuous Schumann resonance background (e.g. Boccippio et al., 1995; Burke and Jones, 1996; Huang et al., 1999).

Finally, radar reflectivity $(\mathrm{Z})$ products are provided by the dual polarization $\mathrm{C}$-band Doppler weather radar located in Barrancabermeja of the Colombian Instituto de Hidrología, Meteorología y Estudios Ambientales (IDEAM). It makes volumetric measurements every 8 minutes with 6 elevations and a gate resolution of 100 meters Cáceres (2017). Although the radar scan strategy was configured to sample the precipitation, the highest 2 elevations were able to measure heights from 8 to $17 \mathrm{~km}$ for distances from 30 to $67 \mathrm{~km}$ where the investigated flash occurred. The derived products used in this study are the maximum $\mathrm{Z}\left(\mathrm{Z}_{\max }\right)$, which corresponds to the maximum $\mathrm{Z}$ observed in the column at the gate position, and the contoured-frequency-altitude diagram (CFAD) of $\mathrm{Z}$ along the corresponding locations of lightning leaders during ASIM video frames. The CFAD (Yuter and Houze, 1995) is a two-dimensional histogram of radar reflectivity with height. The CFADs provide information on changes in the vertical distribution of radar reflectivity that help to identify the cloud depth and hydrometeors types above the altitude of the lightning leaders. For instance, narrow distributions with height imply homogenous precipitating sized particles, while bi-modal or broad distributions mean different types or size of hydrometeors.

\section{Results}

On November $22^{\text {nd }} 2018$, a lightning flash occurred at 08:57:21.4413 UT near Barrancabermeja (Colombia) at $\sim 7.4^{\circ}$ latitude and $-73.85^{\circ}$ longitude (Figure 1). The flash was in a cell of a large nighttime thunderstorm system within the coverage of the Colombia LMA in Barrancabermeja and ranging from 36 to $67 \mathrm{~km}$ from the radar. The initial part of the flash was outside the field of view of the MMIA sensors (white markers in the south-east view in Figure 1a and b) in a region with cloud top temperatures between

This article is protected by copyright. All rights reserved. 
$-73^{\circ} \mathrm{C}$ and $-75^{\circ} \mathrm{C}$, corresponding to heights of $\sim 14.5 \mathrm{~km}$ according to ERA-INTERIM reanalysis (Dee et al., 2011). The part of the flash observed by ASIM (Figure 1c and black filled markers in Figure 1a and b) mostly developed in a less deep region with warmer cloud top temperatures of $-66^{\circ} \mathrm{C}$ to $-68^{\circ} \mathrm{C}(\sim 13.5 \mathrm{~km})$. For later analysis, the five regions (boxes) depicted in Figure 1-b and 1-c will be used to relate features of optical observations with lightning processes and cloud properties.

\subsection{The lightning flash}

The flash originated at $7.223 \%-73.91^{\circ}$ in the coldest cloud top (marker a in Figure 2). LMA sources in Figure 2 show that the flash initiation was at a height of $5 \mathrm{~km}$ with a negative leader propagating upwards at $\sim 10^{5} \mathrm{~m} \mathrm{~s}^{-1}$ up to $11 \mathrm{~km}$. After $\sim 50 \mathrm{~ms}$ (b), new negative leaders appeared at the same location as the previous one and expanded simultaneously to southward and northward directions for $450 \mathrm{~ms}$ (b-c). During this period, sources associated with positive leader breakdown were identified at a lower level, $\sim 5 \mathrm{~km}$ altitude. The negative and positive leaders during the first $500 \mathrm{~ms}$ period of the flash (a-c) revealed the existence of positive polarity electric charge between 6 to $11 \mathrm{~km}$ altitude and negative electric charge below $5 \mathrm{~km}$.

At $441.85 \mathrm{~s}$ new IC breakdown occurred at the north-end of the flash (c') at the time when a negative CG (-CG) stroke of $-24 \mathrm{kA}$ was detected by LINET and WWLLN. From the location of the $-\mathrm{CG}$ stroke, slow negative leaders $\left(<10^{5} \mathrm{~m} \mathrm{~s}^{-1}\right)$ expanded radially $5 \mathrm{~km}$ for $150 \mathrm{~ms}$ ( $\mathrm{c}^{\prime}-\mathrm{d}$ and LMA sources in Box 1, Figure 1). After this time (d), a fast negative leader $\left(\sim 10^{5} \mathrm{~m} \mathrm{~s}^{-1}\right)$ was initiated from this area and propagated towards the east into a stratiform region for about $175 \mathrm{~ms}$ (d-f) and progressively descending from $9 \mathrm{~km}$ to $7 \mathrm{~km}$ altitude branching $40 \mathrm{~ms}$ (e) before ending (sources in Box 2, Figure 1). After the end of this leader (f), a positive $+C G$ stroke with $11 \mathrm{kA}$ occurred close to the location (f') of the earlier-CG stroke. As can be deduced from the presence and characteristics of the ELF transient waveform, the initiation of fast intracloud negative leaders (van der Velde and Montanyà, 2013; and van der Velde et al., 2014) and using a similar optical discrimination criterion as Bitzer (2016), we assume that this $+\mathrm{CG}$ produced continuing current. During this continuing current phase, a fast horizontal negative leader $\left(0.410^{6} \mathrm{~m} \mathrm{~s}^{-1}\right)$ at $<7 \mathrm{~km}$ extended the propagation of the flash further east $(\mathrm{g}-\mathrm{h})$. This leader presented two

This article is protected by copyright. All rights reserved. 
branches extending simultaneously towards the south-east (f-g and Box3, Figure 1) and to the north (f-h and Box 4, Figure 1). From the leader at the north, a branch propagated at $0.510^{6} \mathrm{~m} \mathrm{~s}^{-1}$ towards the north-east (h-j and Box 5, Figure 1). The flash ended with the end of this leader propagation followed by a short-isolated breakdown (k) at the northeast of the two CG locations.

In summary, this two-stroke bipolar CG flash started in a convective core of the storm with leaders propagating for $500 \mathrm{~ms}$. A -CG stroke occurred at the north end of the previous leader activity followed by negative leader propagation into the stratiform region of the cloud for $300 \mathrm{~ms}$. A +CG stroke followed at the location of the previous -CG stroke. This + CG stroke produced continuing current likely supplied by the propagation of a fast negative leader.

\subsection{MMIA photometer, GLM and ISS-LIS radiances}

Altitudes of the located LMA sources versus time during MMIA detections are plotted in Figure 3a. Radiances measured by MMIA in the three spectral bands $(337.0 \mathrm{~nm}, 777.4$ $\mathrm{nm}$ and 180-230 nm) are depicted in Figures 3-b, c and d. Radiances of ISS-LIS (red line) and GLM (black line) have been computed by integrating radiances from all the events detected every $2 \mathrm{~ms}$ frame (Figure 3-c). Since both ISS-LIS and GLM observe the 777.4 $\mathrm{nm}$ spectral band, there is very high consistency with the same MMIA photometer spectral band (red line in Figure 3-b). Note that ISS-LIS (red line) radiance stops before GLM (black line) because the flash was no longer in the field of view of the sensor.

Inspecting the photometer radiances (Figure 3-b), after $442.05 \mathrm{~s}$, the blue and red channels showed a progressive increase of radiance superimposed with small surges. At $442.15 \mathrm{~s}$ the red signal abruptly increased producing several peaks just before the $+\mathrm{CG}$. This increase was also present in the GLM and ISS-LIS radiances. Just after the time of the $+\mathrm{CG}$ stroke, the peak was more pronounced in the red than in the blue band. The red pulse presented faster rise and decay times $(2.2 / 12.9 \mathrm{~ms})$ compared to the blue (5.4/71.1 $\mathrm{ms})$. Starting right after the $+\mathrm{CG}$ stroke, the ELF magnetic field signal measured in Cape Verde (Figure 3-e) suggests the presence of continuing current. This continuing current is noticeable in the ELF signal for about $30 \mathrm{~ms}$ that corresponds to a decay to about $25 \%$ of the peak value in the MMIA red and GLM radiances. The presence of continuing 
current during this period is also supported by the identified LMA sources of a fast (0.4 $10^{6} \mathrm{~m} \mathrm{~s}^{-1}$ ) negative leader. Note that the transients in the magnetic field occurring after $442.25 \mathrm{~s}$ (Figure 3-e) might belong to a different flash, according to the detection of a distant flash at that time by GLM. The small signal in the MMIA 180-230 nm photometer (Figure 3-d), seems to present a small increase at the time of the $+\mathrm{CG}$, and behaves more similarly to the blue band although its amplitude is more than three orders of magnitude smaller.

\subsection{MMIA imaging data and weather radar}

In the last four video frames recorded by MMIA, the flash was entirely in the field of view, so the previous frames have been omitted in this study. The periods of each video frame are indicated with vertical lines in Figure $3 \mathrm{~b}$ and displayed in Figure 4. The four camera images of ASIM are shown in Figure 4 with the blue channel $(337 \mathrm{~nm})$ images in the left column and the red channel $(777.4 \mathrm{~nm})$ images in the right column. The location of the investigated boxes on the MMIA images can be easily identified in Figure 1c.

In the video frame 1 (Figure 4-a) the luminosity of the flash comes from the location of the -CG stroke that occurred $125 \mathrm{~ms}$ before the frame start and where the LMA detected some negative leader breakdown activity (Box 1 in Figure 1b and c). During frame 1, the LMA detected a new leader propagating out of what will become the main luminosity core towards the east (Box 2). This new leader is seen in both cameras, but remained undetected by GLM and ISS-LIS. The radar cross-sections along the LMA sources during this frame indicate that the sources occurred above the altitude of the $20 \mathrm{dBZ}$ reflectivity echo tops. During frame 2, the leader entered into a more stratiform region (Box 2) with reflectivity $<15 \mathrm{dBZ}$ echo tops above the leader height $(8 \mathrm{~km})$ and coldest cloud top temperature of $-67^{\circ} \mathrm{C}(13.5 \mathrm{~km})$. The leader is clearly seen in both MMIA cameras (Figure 4-b) and GLM reports events within the high radiance region in the red MMIA image. At the beginning of frame 3 (Figure 4-c), a +CG stroke located in Box 1 triggered a fast negative leader $\left(0.410^{6} \mathrm{~m} \mathrm{~s}^{-1}\right)$ that propagated and branched during the frame exposure. The branch towards the southeast (Box 3) produced more LMA sources than the branch that propagated to the north (Box 4) but only the latter is well identified in the red image. Figure 4-d depicts frame 4 where the leader propagating to the north-east (Box 5) can be more easily distinguished in the red image than in the blue. It is also remarkable that the section of leader end appears brighter than its channel behind. The north-east

This article is protected by copyright. All rights reserved. 
branch (Box 5) is responsible for the radiance peak after $442.25 \mathrm{~s}$ in the MMIA red channel photometer (Figure 3-b) and GLM (Figure 3-c), this will be discussed in the section 4.2.

To relate cloud properties with the optical observations, two-dimensional histograms of radar reflectivity with height, contoured-frequency-by-altitude diagrams (CFAD) are computed along the leader propagation paths in Figure $1 \mathrm{~b}$ and shown in Figure 5. Box 1 corresponds to the area where the CG strokes were located; and Box 2 includes the area within \pm 1 radial gate (representing $750 \mathrm{~m}$ width) along the central leader channel mapped by the LMA during frames 1, 2 before it branches. Box 3 and 4 are analogous to Box 2 for southeast and north branches during frames 3 and 4, respectively; and the same in Box 5 of the leader branch towards the northeast. In each CFAD, the altitude of the leader is indicated by the heavy horizontal dashed line whereas the $50^{\text {th }}$ and $90^{\text {th }}$ percentiles of the cumulative reflectivity $\mathrm{Z}$ are indicated by the solid and dashed lines, respectively.

The LMA sources within Box 1 are located at an altitude of $\sim 9 \mathrm{~km}$ (Figure 2). At this altitude, the CFAD (Figure 5-a) shows a thinner region with weak $\mathrm{Z}$ values with $90 \%$ of the reflectivity below $18 \mathrm{dBZ}$. In this area, the maximum radiances of the flash in both spectral channels are found in frame 3 (Figure 4-c) when the $+\mathrm{CG}$ stroke occurred. The peak in the measured red photometer is higher than the one recorded by the blue photometer. In the same region defined by Box 1, the blue signal surpasses the red after the continuing current during frame 5 (figure 4-d). In Box 2, the CFAD shows a shallow cloud above the leader height at $\sim 8 \mathrm{~km}$ with $90 \%$ of the reflectivity below $\sim 17 \mathrm{dBZ}$. This low reflectivity and the shallow cloud above the leader channel did not prevent the lightning leader at this location to be imaged in frames 1 and 2. Much higher reflectivity $<23 \mathrm{dBZ}$ is found above the south-west lightning leader channel in Box 3 that propagates at $7.5 \mathrm{~km}$ altitude. Although Box 3 has low cloud tops according to the radar and satellite images, and the lightning leader channel is close to the top, the high reflectivity above the channel is an indication of high concentration and/or large size of cloud particles. The dense cloud in Box 3 could be responsible for the almost undetectable luminosity from the lightning channels there. In Box 4, the north leader channel propagates during frame 3 at an altitude of $7 \mathrm{~km}$ with a reflectivity of the cloud above it of $<18 \mathrm{dBZ}$. In this area luminosity of the leader is much higher in the red than in the blue image (Figure 3-c). Finally, the cloud in Box 5 has convective characteristics as indicated by its cloud tops in 
Figure 1 and the reflectivity profile in Figure 5. The north-east leader in Box 5 during frame $4 \mathrm{~d}$ is clear in the red image and well tracked by GLM, but highly attenuated and diffuse in the blue. The leader travels at $7 \mathrm{~km}$ and above this level we found reflectivity of $<20 \mathrm{dBZ}$.

\section{Discussion}

\subsection{Radiances and radar reflectivity}

The average blue $(337.0 \mathrm{~nm})$ and red $(777.4 \mathrm{~nm})$ radiances observed by the ASIM cameras of the five selected boxes are shown in Figure 6.

At the location of the CG strokes (Box 1), lightning leader sources are identified at an altitude of $\sim 9 \mathrm{~km}$ with a shallow cloud of low reflectivity ( $<18 \mathrm{dBZ}$ ) above it. This may have produced little attenuation compared to other deeper areas. The ratio of the received red to blue starts with values from $\sim 1.85$ during the frames 1 and 2 before the + CG stroke. At the time of the $+\mathrm{CG}$ stroke (frame 3), radiances peak and the ratio increases to 2.2. The ratio remains higher than 1 for the $30 \mathrm{~ms}$ corresponding to the continuing current phase until both radiances equalize. Later, in frame 4 , the ratio of the average radiance decreases to 0.9 ( 0.6 for the peak radiances not shown in Figure 6 ), meaning that the received blue radiance is more intense than the red. From Figures 3 and 4, the consistency of the red radiance with the continuing current suggests that the observed red channel (777.4 nm) oxygen atomic line is more related with the evolution of lightning currents than the blue band. The relation of red radiance pulses with impulsive lightning current events identified by the LMA was previously observed by Thomas et al. (2000). In the laboratory, Windmar et al. (1991) found a proportional relation of the peak amplitude of the red radiance with the kiloampere current of a long spark. The relation of the $777.4 \mathrm{~nm}$ emission is related with hot lightning channels $(>4000 \mathrm{~K})$ or sparks that provide thermal excitation of the ${ }^{5} \mathrm{P}$ electronic state of atomic oxygen (see the interpretation in Soler et $a l ., 2020)$. In Box 1 the slow decay of the blue signal different to the red may indicate the prevalence of streamer/corona or other low temperature discharge activity, in particular, at the region of the location of the CG strokes. So, whereas the reduction of the red emission has been related to the decay of the continuing current, the prevalent blue optical emissions are assumed to come from the streamer/corona accompanying the high-

This article is protected by copyright. All rights reserved. 
altitude negative leader channel at this region. This channel is the root of the channels progressing along the other boxes. Blue emissions are common in streamer and corona discharges and are related to the $\mathrm{N}_{2} 2^{\text {nd }}$ positive system and the $\mathrm{N}_{2}{ }^{+} 1^{\text {st }}$ negative system (e.g. Soler et al. 2020 and references therein). In the laboratory, works such as Machala et al. (2011) and Janda et al. (2016) showed the emission of the $\mathrm{N}_{2} 2^{\text {nd }}$ positive system at the $337.0 \mathrm{~nm}$ being associated with the streamer phase of a spark discharge. So, the identified prevalence of the blue signal might be related to the evolution of the electric fields related with the leaders and the cloud.

The radiance in Box 2 includes the leader channel emerging from the location of the CG strokes at frame 1 . This negative leader propagated at $10^{5} \mathrm{~m} \mathrm{~s}^{-1}$ and ended at the time of the $+\mathrm{CG}$ (frame 3). From this central leader channel two branches occurred after the $+\mathrm{CG}$ corresponding to the LMA sources in Box 3 and 4. At the time of frame 3, the central leader channel presented higher red radiance than its south-east, north and north-east branches in Boxes 3, 4 and 5, respectively. As seen in Figure 5 and Figure 6, at the regions of the south-east (Box 3), north (Box 4) and north-east (Box 5), the cloud above the leader was thicker in terms of reflectivity than in Box 2 . This thicker cloud mostly affected the blue band. This is reflected in the ratios of the average radiance in Figure 5-b, c, $d$ and e at the time of frame 3 corresponding to 2.9 (18 dBZ), 3.8 (23 dBZ), 4 (18 dBZ) and 5.4 (20 dBZ), respectively. The reflectivity in parentheses correspond to the maximum above the leader. During this frame, the charge that feeds the continuing currents to ground is assumed to be provided by the south and north leader branches based on the fast propagation $\left(0.410^{6} \mathrm{~m} \mathrm{~s}^{-1}\right)$ of the leaders and their higher radiances compared to the extension of the north-east leader.

One of the salient features of the observation is the imaged north-east leader branch (Box 5 ) by the red camera at frame 4 (Figure 4-d). This leader end produced an increase in the $777.4 \mathrm{~nm}$ radiance after $442.25 \mathrm{~s}$ (Figure $3 \mathrm{~b}$ ) which is not observed in the blue channel image. The level of the blue radiance in Box 5 during frame 4 corresponds almost to the background level and it is lower than the corresponding radiance at the same frame but in the leader channel behind in Box 2. For comparison, the red radiance during frame 4 is $~ 1.2$ times greater in Box 5, at the leader end, compared to its trailing channel in Box 4 and Box 2 although Box 5 had the deepest cloud above the leader. This negative correlation between the radiance and radar reflectivity suggests that the detected surge in

This article is protected by copyright. All rights reserved. 
the radiation might be related with the occurrence of some intra-cloud process involving high currents (e.g. recoil leader event) at the leader end in Box 5.

In addition, taking into account that the used weather radar is more sensitive to the backscatter of ice and water particles and these precipitating ice particles are related to icy cloud particles (Baker et al.,1999), it is plausible to state that the higher the ice content above $8 \mathrm{~km}$ the higher will be the concentration of cloud ice particles. Moreover, the broader the CFAD distributions above the freezing level, the more ice cloud particles are produced reflecting higher updrafts that consequently produce more super-saturation. Therefore, the optical emissions would be more attenuated depending on the concentration and the size of ice particles above the leader (Brunner and Bitzer, 2020, Rutledgle et al., 2020) as well as on the water vapor (Thomason and Krider 1982) that fed those particles. At Box 3, the higher and large sized ice cloud particles concentration attenuated both the red and blue channels, while at Boxes 4 and 5, the presence of more water vapor and smaller ice cloud particles might have contributed to enough attenuation of both spectral bands. The north and north-east leaders (Box 4 and 5) may have produced sufficiently high currents to generate detectable levels of red emissions. In the Section 4.3 a quantitative analysis of the cloud optical depths at the considered regions is presented.

In summary, the red radiance is close related to the occurrence of the currents on the leader channels according to the identified CG strokes, continuing currents and the recoil leader event consistently with previous works (e.g. Thomas et al., 2000). The longer time decay of the blue emissions relative to the red and their lower correlation with the evolution of the currents can be indicative that these blue emissions are related to the streamer zones of the leader channels according to the nature of the blue emission $\left(\mathrm{N}_{2}\right.$ $2^{\text {nd }}$ positive system). So, blue emissions would be related to the evolution of the electric fields of the leader and the cloud. Nevertheless, the detected blue radiation allows imaging of the leader channels in the regions with less cloud above the lightning flash.

\subsection{Surges of radiance associated with leader branching}

The small surges in red and blue emissions at $442.127 \mathrm{~s}$ in Figure $3 \mathrm{~b}$ during frame 2 (marker e) are related to a new branch of the developing leader. This branch continues for $40 \mathrm{~ms}$ until the time of the +CG stroke. This leader branch can be associated with the 
downward positive leader approaching the ground, including the last $12 \mathrm{~ms}$ where both the blue and red radiances increased, oscillating in the red. This oscillation is consistent with the impulsive optical emissions by recoil leader events (K-changes) analysed by (Montanyà et al. 2012) using high speed video during the development of positive leader to ground. Impulsive red optical emissions related to recoil leader events were previously reported by Thomas et al. (2000). About $50 \mathrm{~ms}$ after the +CG stroke (frame 3), at 442.226 $\mathrm{s}$, a new radiance surge in the red channel is associated with new negative leader branches (from $\mathrm{g}$ and $\mathrm{h}$ in Figure 2) propagating for $20 \mathrm{~ms}$ with speeds $0.410^{6} \mathrm{~ms}^{-1}$ (Box 3, 4). Finally, the red surge at $442.256 \mathrm{~s}$ in frame 4, Box 5, also occurred in association with a leader branching and further propagation ( $\mathrm{i}-\mathrm{j}$ in Figure 2). In the blue photometer, these surges are unnoticed at the indicated times although there are some smoothed and delayed pulses that might be related. This is the case of the peak in the blue at $442.226 \mathrm{~s}$ occurring $7 \mathrm{~ms}$ after the peak in the red (Figure 3-b). If both peaks are related, then the significant delay might be due to the blue radiance originating from the region of the CG stroke (Box 1) whereas the red originates from the location of the leader branching (Box 3, 4). Possible delays due to higher scattering in the blue than in the red are possible (e.g. Luque et al., 2020).

\subsection{Optical depth}

Light et al. (2001) and Beirle et al. (2014), among others, stated that clouds mostly affect the propagation of light causing spatial smearing via multiple scattering. Light absorption by ice and water at the $337.0 \mathrm{~nm}$ and $777.4 \mathrm{~nm}$ is small (e.g. Warren, 1984; Thomason and Krider, 1982; Light et al., 2001; Warren and Brandt, 2008) but the absorption and scattering differences can be significant between the two wavelengths (Luque et al., 2020). Some previous works (e.g. Thomason and Krider, 1982; Koshak et al., 1994; Thomas et al. 2000; Light et al. 2001, Brunner and Bitzer, 2020) found that the optical depth between the light source and the cloud edges including the horizontal extension of the cloud (Koshak et al., 1994) highly affects the detectability of lightning. These works also indicate the need to know the location and the progression of the source within the cloud. Rutledge et al. (2020) found that optical emissions are not completely correlated with the ice water path above individual lightning flashes derived from radar data because the precipitating particles detected by radar are not necessarily the main reason for the

This article is protected by copyright. All rights reserved. 
light attenuation. Small undetectable cloud particles may have higher concentrations and so can produce collectively higher light attenuation than precipitation-size particles.

We now attempt to evaluate the effects of the cloud on the light propagation at the investigated regions of the flash. Due to the radar limitations, we adopt the cloud particle distribution from vertical radar reflectivity and temperature profiles using the parametrization by Heymsfield et al. (2002 and 2013). The calculated particle distributions at each level are limited from a minimum diameter of $20 \mu \mathrm{m}$ up to a parametrized maximum diameter. Optical depth of the cloud sections above the lightning leader channels at each box are calculated by following Thomason and Krider (1982). Optical depths are limited up to an altitude of $10 \mathrm{~km}$ because, as pointed out by Rutledge et al. (2020), we found unrealistically high particle densities for the low temperatures at higher levels. Details on the calculations of particle distribution and optical depth are provided in the Appendix section of this paper. Results of the estimated optical depths are presented in Table 1. The values are relative to the optical depth in Box 1. We present relative optical depths because of the high sensitivity of the cloud particle distribution on the temperature (Heymsfield et al. 2002 and 2013). Despite this dependence, the relative optical depths between boxes remain almost independent to temperature offsets. The calculated relative optical depths are consistent with some of the characteristics of the observed radiance from each box. The lower optical depth of Box 2 relative to Box 1 is in accordance with the more stratiform nature of the cloud in this region where the red and blue radiances were less effected by cloud. The reduction of $50 \%$ of the optical depth in Box 2 results from the decrease of $3 \mathrm{dBZ}$ and a shallower cloud above the leader compared to Box 1. In contrast, Box 3 presents the highest relative optical depth $\sim 2$ coinciding with the region with the almost undetected blue and red radiances. Compared to Box 1 , despite the fact that the median reflectivity above the leader is $1 \mathrm{dBZ}$ higher, the maximum reflectivity $\left(90^{\text {th }}\right.$ percentile) is $6 \mathrm{dBZ}$ greater and with lower lightning leader channel height. In between, the 0.9 relative optical depth of Box 5 allowed the detection of the red emissions but strongly attenuated the blue. Figure 1a shows a higher cloud top in Box 5 if compared to Box 4 and similar to the cloud tops in Box 1. The median reflectivity in Box 5 at the leader altitude is $2 \mathrm{dBZ}$ lower than in Box 1 whereas the reflectivity corresponding to the $90^{\text {th }}$ percentile is $3 \mathrm{dBZ}$ higher.

In summary, to overcome the limitation of radar on the detection of cloud particles the parametrized ice particle size distributions employed have provided consistent relative

This article is protected by copyright. All rights reserved. 
optical depth with the optical observations. Consistently with Brunner and Bitzer (2020), the results highlight the importance on the combination of the light emission by different lightning processes and the optical depth features due to cloud ice particles surrounding the lightning channels at high cloud altitudes $(>7 \mathrm{~km})$. The location at Box 1 where the return stroke currents produced high channel luminosity and with low cloud optical depth due to lightning channels at high altitudes, would be evidence of the CG features pointed out by Zhang and Cummins (2020) to produce high detection efficiency of CG flashes by GLM. In the area of the lowest relative optical depth (Box 2) corresponding to a stratiform region, the propagation of negative lightning leaders has been optically resolved by MMIA and GLM. The detection of this leader by GLM might have been made possible by the occurrence of a branching of the leader that produced a surge in the radiance (marker e in Figure 3-b) if compared to the undetected leader by GLM in frame 1 (Figure 4-a). The increase of a factor of 2 on the relative optical depth in Box 3 attenuated the optical emissions of a fast negative leader producing abundant LMA sources. The undetected leader did not present any feature such as branching or recoil leader that might had involved a surge in channel luminosity. Box 5 with lower optical depth than Box 1 and a surge in radiance, allowed GLM to image the propagation of the leader (Figure 4d) all along the channel from the tip to the location of the former CG. Our results complement the recent study by Rutledge et al. (2020). Instead of using the ice water path derived from radar we have estimated the cloud particle size distribution from parametrization data and we have found consistency with the observations. In addition, we have investigated the features in different parts of the flash considering their cloud and lightning features. Nevertheless, for a precise evaluation of the light escaping from the cloud, cloud edges and the horizontal cloud extension (Koshak et al., 1994) should not be omitted.

\section{Conclusions}

We have presented concurrent measurements of a lightning flash from space by ASIM, GLM, ISS-LIS and from the ground by the Colombia-LMA, WWLLN, a local weather radar, and an ELF electromagnetic wave receiver. This observation has provided the means for interpretation of the optical observations with respect to lightning leader processes. This flash included negative and positive strokes as well the occurrence of continuing currents. In addition, weather radar data allowed estimation of the attenuation 
of optical radiance by the clouds above the lightning leaders at different locations along the path of the lightning channel propagation.

The following summarizes our findings:

- Surges in the photometer radiance, especially in red $(777.4 \mathrm{~nm})$, besides return stroke and recoil leader processes have been found to be associated with lightning leader branching involving new leader development. These surges associated to leader branching are not always noticed in the blue $(337.0 \mathrm{~nm})$ signals, so these processes appear not to involve significant emissions in this wavelength.

- The radiance at red correlates with the continuing current identified from the magnetic ELF signals, the fast leader development detected by the LMA and the continuous radiance.

- The oscillations in the red signal photometer just before the $+\mathrm{CG}$ stroke are probably recoil leader events during the downward propagation of the leader to ground prior to the return stroke.

- Based on the above, the detected red signals are likely from the highly conducting hot leader channels and associated with high luminosity of the channel involving impulsive and continuing current processes.

- The camera images showed long persistence of blue radiation at the location of the $+\mathrm{CG}$ stroke after the decay of the continuing current and even surpassing the detected red radiance.

- The blue emission has been shown to not be closely related to lightning current processes. The nature of the $\mathrm{N}_{2} 2^{\text {nd }}$ positive system optical emission suggests the origin from non-thermal discharges (streamers) on the leader channels and probably in the thundercloud.

- The detected blue radiation allowed imaging of the leader channels especially in the stratiform areas with low cloud tops.

- Cloud depth or cloud thickness above the lightning channels appears to attenuate more to the blue emission more than the red.

- Relative optical depths at different parts of the cloud where lightning leaders propagated have been estimated from radar and temperature data using parametrized models of particle size distribution.

This article is protected by copyright. All rights reserved. 
- Besides the position of the lightning leaders and the properties of the cloud above and around them, detection of optical emissions of lightning depends on the different lightning processes, which can be inferred from their temporal and spectral properties.

\section{Acknowledgments}

This work was supported by research grants from the Spanish Ministry of Economy and the European Regional Development Fund (FEDER): ESP2013-48032-C5-3-R, ESP2015-69909-C5-5-R, ESP2017-86263-C4-2-R and PID2019-109269RB-C42. ASIM is a mission of ESA's SciSpace Programme for scientific utilization of the ISS and nonISS space exploration platforms and space environment analogues. It is funded by ESA and national contributions through contracts with TERMA and Technical University of Denmark (DTU) in Denmark, University of Bergen (UB) in Norway and University of Valencia (UV) in Spain. The ASIM Science Data Centre (ASDC) at DTU is supported by PRODEX contract PEA 4000115884 . The authors are grateful to Keraunos for providing LINET lightning data and the World Wide Lightning Location Network (http://wwlln.net/) for providing WWLLN lightning location data. Also, we would like to thank the Colombian Instituto de Hidrología, Meteorología y Estudios Ambientales (IDEAM) for providing the weather radar information used in this study.

\section{Data availability}

Data associated with this work is available at https://zenodo.org/record/4530914. Data access to ASIM is available by registering at https://asdc.space.dtu.dk/. GLM data are available from NOAA (GOES-R Series Program, 2019, https://data.nodc.noaa.gov/cgibin/iso?id=gov.noaa.ncdc:C01527\#) and ISS-LIS from NASA Global Hydrology Resource Center (Blakeslee et al. 2019, https://ghrc.nsstc.nasa.gov/pub/lis/iss/data/science/nqc/hdf/). The ABI imagery can be accessed from the NOAA's Comprehensive Large Array Storage Service (CLASS) or the Google (gcp-public-data-goes-16) or Amazon cloud.

This article is protected by copyright. All rights reserved. 


\section{References}

Aranguren, D., López, J., Inampués, J., Torres, H., and Betz, H. D. (2017). Cloud-to-ground lightning activity in Colombia and the influence of topography Journal of Atmospheric and Solar-Terrestrial Physics, doi: 10.1016/j.jastp.2016.08.010.

Baker, M. B., Blyth, A. M., Christian, H. J., Latham, J., Miller, K. L., and Gadian, A. M. (1999). Relationships between lightning activity and various thundercloud parameters: satellite and modelling studies. Atmospheric Research, 51, 221-236.

Beirle, S., Koshak, W., Blakeslee, R., and Wagner, T., (2014). Global patterns of lightning properties derived by OTD and LIS. Nat. Hazards Earth Syst. Sci., 14, 2715-2726.

Bitzer, P. M. (2017). Global distribution and properties of continuing current in lightning. J. Geophys.Res. Atmos., 122, 1033-1041, doi:10.1002/2016JD025532.

Betz H. D., Schmidt, K., and Oettinger W. (2009). LINET - An International VLF/LF Lightning Detection Network in Europe. Lightning: Principles, Instruments and Applications. Springer, doi: 10.1007/978-14020-9079-0_5.

Blakeslee, R. J. (2019). Non-Quality Controlled Lightning Imaging Sensor (LIS) on International Space Station (ISS) Science Data. NASA EOSDIS Global Hydrology Resource Center Distributed Active Archive Center, Huntsville, Alabama, U.S.A. doi:10.5067/LIS/ISSLIS/DATA107. [Accessed: 11 March 2020]

Blakeslee, R. J., Lang, T. J., Koshak, W. J., Buechler, D., Gatlin, P., Mach, D. M., Stano, G. T., Virts, K. S., Walker, T. D., Cecil, D. J., Ellett, W., Goodman, S. J., Harrison, S., Hawkins, D. L., Heumesser, M., Lin, H., Maskey, M., Schultz, C. J., Stewart, M., Bateman, M., Chanrion, O., and Christian, H. (2020). Three years of the Lightning Imaging Sensor onboard the International Space Station: Expanded Global Coverage and Enhanced Applications. Earth and Space Science, https:/doi.org/10.1002/essoar.10502896.1.

Boccippio, D. J., Williams, E. R., Heckman, S. J., Lyons, W. A., Baker, I. T., and Boldi, R. (1995). Sprites, ELF transients, and positive ground strokes. Science, 269, 1088.

Burke, C. P., and Jones, D. L. (1996). On the polarity and continuing currents in unusually large lightning flashes deduced from ELF events. J. Atmos. Terr. Phys., 58, 531.

Brunner K. N., and Bitzer, P. M. (2020). A first look at cloud inhomogeneity and its effect on lightning optical emission. Geophysical Research Letters, 47, e2020GL087094. https://doi.org/ 10.1029/2020GL087094.

This article is protected by copyright. All rights reserved. 
Cáceres-Leon, R. (2017). Meteorología Aplicada a la Seguridad de las Operaciones Aéreas, Colección Ciencia y Poder Aéreo, ISBN: 978-958-59961-1-3.

[Available online: https://libros.publicacionesfac.com/index.php/libros/catalog/book/22].

Chanrion, O., Neubert, T., Lundgaard Rasmussen, I., et al. (2019). The Modular Multispectral Imaging Array (MMIA) of the ASIM Payload on the International Space Station. Space Sci. Rev., 215, 28. https://doi.org/10.1007/s11214-019-0593-y.

Christian, H. J., and Goodman, S. J. (1987). Optical observations of lightning from a high altitude airplane. J. Atmos. Ocean. Tech., 4, 701-711.

Christian, H. J., R. J. Blakeslee, and S. J. Goodman (1989), The detection of lightning from geostationary orbit, J. Geophys. Res., 94, 13329-13337.

Dee, D. P., Uppala, S. M., Simmons, A. J., Berrisford, P., Poli, P., Kobayashi, S., ... and Bechtold, P. (2011). The ERA $\square$ Interim reanalysis: Configuration and performance of the data assimilation system. Quarterly Journal of the Royal Meteorological Society, 137(656), 553-597.

Erdmann, F., Defer, E., Caumont, O., Blakeslee, R. J., Pédeboy, S., and Coquillat, S. (2020). Concurrent Satellite and ground-based Lightning Observations from the Optical Lightning Imaging Sensor (ISS-LIS), the LF network Meteorage and the SAETTA LMA in the northwestern Mediterranean region. Atmos. Meas. Tech., 13, 853-875.

GOES-R Algorithm Working Group and GOES-R Series Program, (2018): NOAA GOES-R Series Geostationary Lightning Mapper (GLM) Level 2 Lightning Detection: Events, Groups, and Flashes. NOAA National Centers for Environmental Information. doi:10.7289/V5KH0KK6.

Goodman, S. J., H. J. Christian, and Rust, W.D. (1988). Optical pulse characteristics of intracloud and cloud-to ground lightning observed from above clouds, J. Appl. Met., 27, 1369-1381.

Goodman, S. J., Blakeslee, R. J., Koshak, W. J., Mach, D., Bailey, J., Buechler, D., Carey, L., Schultz, C., Bateman, M., McCaul, E., and Stano, G. (2013). The GOES $\square$ R Geostationary Lightning Mapper (GLM). Atmospheric Research, 125 $\square 126,34-49$.

Heymsfield, A. J., Bansemer, A. , Field, P. R., Durden, S. L., Stith, J., Dye, J. E., Hall, W., and Grainger T. (2002). Observations and parameterizations of particle size distributions in deep tropical cirrus and stratiform precipitating clouds: Results from in situ observations in TRMM field campaigns. J. Atmos. Sci., 59, 3457-3491.

This article is protected by copyright. All rights reserved. 
Heymsfield, A. J., Schimitt, C., and Bansemer, A. (2013). Ice Cloud Particle Size Distributions and Pressure-Dependent Terminal Velocities from In Situ Observations at Temperatures from $0^{\circ}$ to $-86^{\circ} \mathrm{C}$. $J$. Atmos. Sci., 70, 4123-4154.

Huang, E., Williams, E., Boldi, R., Heckman, S., Lyons, W., Taylor, M., Nelson, T., and Wong, C. (1999). Criteria for sprites and elves based on Schumann resonance observations. J. Geophys. Res., 104(D14), 16943-16964.

Koshak, W. J., Solakiewicz, R. J., Phanord, D. D., and Blakeslee, R. J. (1994). Diffusion model for lightning radiative transfer. J. Geophys. Res., 99, 14361-14371.

Light, T. E., Suczcynsky, D. M., Kirkland, M. W., and Jacobson, A. R. (2001). Simulations of lightning optical waveforms as seen through clouds by satellites. J. Geophys. Res.,106 (D15), 17103-17114. https://doi.org/10.1029/2001JD900051

López J. A., Montanyà, J., van der Velde, O. A., Pineda, N., Salvador, A., Romero, D., Aranguren, D. and Taborda, J. (2019). Charge structure of two tropical thunderstorms in Colombia. J. Geophys. Res.: Atmospheres, doi.org/10.1029/2018JD029188.

Liu, H., and V. Chandrasekar, 2000: Classification of Hydrometeors Based on Polarimetric Radar Measurements: Development of Fuzzy Logic and Neuro-Fuzzy Systems, and In Situ Verification. J. Atmos. Oceanic Technol., 17, 140-164, https://doi.org/10.1175/1520-0426(2000)017<0140:COHBOP>2.0.CO;2.

Luque, A., Gordillo-Vázquez, F. J., Li, D., Malagón-Romero, A., Pérez-Invernón, F. J., Schmalzried, A., Soler, S., Chanrion, O., Heumesser, M., Neubert, T., Reglero, V., and Østgaard N., (2020). Modeling lightning observations from space-based platforms (CloudScat.jl 1.0). Geoscientific Model Development, doi.org/10.5194/gmd-2020-161.

Montanyà, J., van der Velde, O. A., March, V., Romero, D., Solà, G., and Pineda, N. (2012). High-speed video of lightning and X-ray pulses during the 2009-2010 observation campaigns in northeastern Spain. Atmos. Res., 117, doi: 10.1016/j.atmosres.2011.09.013.

Montanyà, J., van der Velde, O. A., Pineda, N., and López, J.A. (2019). ISS-LIS data analysis based on LMA networks in Europe. EUMETSAT Science Studies, [Available online: https://www.eumetsat.int/website/home/Data/ScienceActivities/ScienceStudies/ISSLISDataAnalysisBase donLMANetworksinEurope/index.html\#OB].

Neubert, T., Østgaard, N., Reglero, V., Blanc, E., Chanrion, O., Oxborrow, C. A., Orr, A. , Tacconi, M., Hartnack, O., and Bhanderi, D. D. V. (2019),.The ASIM mission on the International Space Station. Space Sci. Rev., 215:26 https://doi.org/10.1007/s11214-019-0592-z.

This article is protected by copyright. All rights reserved. 
Peterson, M. (2019). Using lightning flashes to image thunderclouds. J. Geophys. Res.: Atmospheres,124. https://doi.org/10.1029/2019JD031055

Peterson, M. J. (2014). Variations of optical and radio lightning characteristics and the relationship between storm convective intensity and above $\square$ cloud electric fields. Dissertation, The University of Utah, $253 \mathrm{pp}$ [Available online at: https://search.proquest.com/openview/2d481bb6a222ae8958de1016fd602870/1?pqorigsite $=$ gscholar\&cbl $=18750 \&$ diss $=\mathrm{y}]$.

Rison, W., Thomas, R., Krehbiel, P., Hamlin, T., and Harlin, J. (1999). A GPS-based three dimensional lightning mapping system: Initial observations in central New Mexico. Geophysical Research Letters, doi: 10.1029/1999GL010856.

Rodger, C.J., Werner, S., Brundell, J. B., Lay, E. H., Thomson, N. R., et al. (2006). Detection efficiency of the VLF World-Wide Lightning Location Network (WWLLN): initial case study. Annales Geophysicae, European Geosciences Union, 24 (12), 3197-3214.

Rutledge, S.A., Hilburn, K. A., Clayton, A., Fuchs B., and Miller, S. D. (2020). Evaluating Geostationary Lightning Mapper flash, Journal of Geophysical Research: Atmospheres, 125, Special Section: A New Era of Lightning Observations from Space. doi: 10.1029/2020JD032827.

Rudlosky, S., Goodman, S. J., and Virts, K. S. (2019a). Lightning detection: Geostationary Lightning Mapper, The GOES $\square$ R series: A new generation of geostationary environmental satellites pp. ISBN-13: 978-0128143278, ISBN-10: 0128143274): Academic Press; Amsterdam, The Netherlands. http://www.worldcat.org/oclc/1127541502.

Rudlosky, S. D., Goodman, S. J., Virts, K. S., \& Bruning, E. C. (2019b). Initial Geostationary Lightning Mapper observations. Geophysical Research Letters, 46, 1097- 1104. https://doi.org/10.1029/2018GL081052

Soler, S., Pérez $\square$ Invernón, F. J., Gordillo $\square$ Vázquez, F. J., Luque, A., Li, D., Malagón $\square$ Romero, A., et al. (2020). Blue optical observations of narrow bipolar events by ASIM suggest corona streamer activity in thunderstorms. Journal of Geophysical Research: Atmospheres, 125, e2020JD032708. https://doi.org/10.1029/2020JD032708

Stuhlmann, R., Rodriguez, A., Tjemkes, S., Grandell, J., Arriaga, A., Bézy, J. $\square$ L., Aminou, D., and Bensi, P. (2005). Plans for EUMETSAT's third generation Meteosat Geostationary Satellite Programme, Advances in Space Research, 36(5), 975- 981.

This article is protected by copyright. All rights reserved. 
Thomas, R. J., Krehbiel, P. R., Rison, W., Hamlin, T., Boccippio, D. J., Goodman, S. J., and Christian, H. J. (2000), Comparison of ground based $3 \square$ dimensional lightning mapping observations with satellite-based LIS observations in Oklahoma, Geophysical Research Letters, 27 (12), 1703-1706. https://doi.org/10.1029/1999GL010845.

Thomas, R. J., Krehbiel, P. R., Rison, W., Hunyady, S., Winn, W., Hamlin, T., and Harlin, J. (2004). Accuracy of the lightning mapping array. Journal of Geophysical Research: Atmospheres, doi: 10.1029/2004JD004549.

Thomason, L. W., and E. P. Krider (1982). The effects of clouds on the light produced by lightning. J. Atmos. Sci., 39, 2051-2065.

van der Velde, O. A., and Montanyà, J. (2013). Asymmetries in bidirectional leader development of lightning flashes. J. Geophys. Res. Atmos., 118, 13,504-13,519, doi:10.1002/2013JD020257.

van der Velde, O. A., Montanyà J., Soula S., Pineda N., and Mlynarczyk J. (2014). Bidirectional leader development in sprite-producing positive cloud-to-ground flashes: Origins and characteristics of positive and negative leaders. J. Geophys. Res. Atmos., 119, 12,755-12,779, doi:10.1002/2013JD021291.

van der Velde, O., Montanyà, J., Neubert, T., Chanrion, O., Lopez, J. A., Fabro, F., Østgaard, N., Goodman, S., and Reglero, V. (2020), Comparison of high-speed optical observations of a lightning flash from space and the ground, Earth and Space Science, https://doi.org/10.1029/2020EA001249.

Warren, S. G. (1984). Optical constants of ice from the ultraviolet to the microwave. Appl. Opt., 23, 12061225 .

Warren, S. G., and Brandt, R. E. (2008). Optical constants of ice from the ultraviolet to the microwave: A revised compilation. Journal of Geophysical Research, 113, D14220. https://doi.org/10.1029/2007JD009744

Yang, J., Zhang, Z., Wei, C., Lu, F., and Guo, Q. (2017). Introducing the new generation of Chinese Geostationary Weather Satellites, Fengyun $\square$ 4. Bulletin of the American Meteorological Society, 98(8), 1637- 1658. https://doi.org/10.1175/BAMS-D-16-0065.1

Yuter, S. E., and Houze Jr., R. A. (1995). Three-dimensional kinematic and microphysical evolution of Florida cumulonimbus. Part II: frequency distributions of vertical velocity, reflectivity, and differential reflectivity. Mon. Wea. Rev., 123, 1941-1963.

This article is protected by copyright. All rights reserved. 
Zhang, D., and Cummins, K. L. (2020). Time evolution of satellite-based optical properties in lightning flashes, and its impact on GLM flash detection. Journal of Geophysical Research: Atmospheres, 125. Special Section: A New Era of Lightning Observations from Space. doi: 10.1029/2019JD032024.

This article is protected by copyright. All rights reserved. 


\section{Figure Captions and Tables}

Figure 1. a) GOES-16 infrared satellite image overlaid with LMA sources. b) Maximum reflectivity $\mathrm{Z}_{\max }$ and LMA sources. White filled circles correspond to LMA sources before ASIM video frame 1 and after frame 4. Black filled squares are LMA sources in the field of view of MMIA. The white squares and the numbers indicate the five analyzed areas of interest (boxes). c) Composition of $777.4 \mathrm{~nm}$ (red) MMIA camera stacked frames with the indication of the five considered areas, LMA sources $d$ and the markers (letters) are used to identify the leaders during the period of the video frames. LINET Cloud-to-ground strokes: negative $(\times)$, positive $(+)$.

Figure 2. LMA data of the flash on 22 November 2018 at 08:57:21.4413 UT. The top panel is altitude of LMA sources versus time (seconds); the left panel is a plan view map; the panels at the right show altitude $(\mathrm{km})$ by latitude and longitude. LMA sources are colored by time. Markers $a$ to $k$ are used as reference in the text. LINET cloud-to-ground strokes (red symbols: $\times$ negative, + positive). The exposure times of the four MMIA video frames are indicated as well the part of the field of view (FOV) of MMIA.

Figure 3. a) LMA; b) ASIM $337 / 4 \mathrm{~nm}$ (blue) and 777.3/5 nm (red) including the reference markers (letters); c) 2 ms-integrated radiances of GLM (black) and ISS-LIS (red); d) MMIA 180-230 nm (UV) photometer; e) Magnetic field measured at the UPC's Cape Verde ELF station. Vertical lines indicate the times of the MMIA video frames 1-4.

Figure 4. Consecutive MMIA camera frames in blue (337.0/4 nm) (left column) and red (777.4/5 nm) (right column) channels. LMA sources (white dots) are overlaid in each image. Locations of GLM events (grey squares) are plotted in the MMIA red images. GLM radiances (grey) at each location are integrated for the time of the frame.

Figure 5. Reflectivity contoured-frequency-by-altitude diagram (CFAD). a) Box 1: location of the CG strokes; b) Box 2: central leader channel emerging from the location of the CG towards east; c) Box 3: southeast leader branch; d) Box 4 north leader branch; e) Box 5: northeast leader branch. Horizontal heavy dashed line indicates the altitude of the leader sources in each box. Solid line marks the $50^{\text {th }}$ percentile of the reflectivity $\mathrm{Z}$ and the dashed line the $90^{\text {th }}$ percentile

This article is protected by copyright. All rights reserved. 
Figure 6. Average radiance of the blue $(337.0 \mathrm{~nm})$ and red $(777.4 \mathrm{~nm})$ from video frames for the boxes 1 to 5. Dot-dash line indicates the altitude of the leader in each box. Solid line corresponds to the $20 \mathrm{dBZ}$ radar echo top.

Table 1. Relative optical depth of the cloud section above the lightning leader channels up to $10 \mathrm{~km}$. Optical depths are relative to Box 1.

Relative optical depth

\begin{tabular}{lc}
\hline \hline Box 1 & 1 \\
Box 2 & 0.5 \\
Box 3 & 2 \\
Box 4 & 0.9 \\
Box 5 & 0.9
\end{tabular}

This article is protected by copyright. All rights reserved. 


\section{Appendix}

Heymsfield et al. (2002 and 2013) have presented assimilation of experimental data to provide ice particle size distributions. One of the common functional forms of the particle size distribution $N(D)$ is the gamma function:

$$
N(D)=N_{o \Gamma} D^{\mu} e^{-\lambda_{\Gamma^{\circ} T}}\left(c m^{-4}\right)
$$

Where $D$ is the particle diameter, $N_{O \Gamma}$ is the intercept, $\lambda_{\Gamma}$ is the slope, and $\mu$ is the shape. The last three parameters are derived from radar and temperature variables as presented by Heymsfield et al. (2002). The simplified equation for the intercept:

$$
N_{o \Gamma}=\frac{Z \lambda_{\Gamma}^{(5.5+\mu)}}{1.210^{8} \Gamma(5.5+\mu)}
$$

Where $Z$ is the radar reflectivity factor $\left(\mathrm{mm}^{6} \mathrm{~m}^{-3}\right)$ converted from observed weather radar measuring in $\mathrm{dBZ}$. Taking into account the use of a C-Band weather radar and measurements above the $0{ }^{\circ} \mathrm{C}, \mathrm{Z}$ can be expressed as (Heymsfield et al., 2002):

$$
Z=10^{\left(\frac{d B Z+7.2}{10}\right)}
$$

where, $7.2 \mathrm{dBZ}$ is to correct the ice/water dielectric constant effect. To simplify, we adopt the median dBZ reflectivity at each level shown in Figure 5. The slope $\lambda_{\Gamma}$ and the shape $\mu$ are estimated from the median fitted functions in Heymsfield et al., (2002), respectively:

$$
\begin{aligned}
\lambda_{\Gamma} & =24 e^{-0.049 T} \quad\left(\mathrm{~cm}^{-1}\right) \\
\mu & =0.13 \lambda_{\Gamma}^{0.64}-2
\end{aligned}
$$

Where $\mathrm{T}$ is the temperature in ${ }^{\circ} \mathrm{C}$. The maximum diameter for each distribution is calculated according to the region of the cloud. For Box 1 and 5 the maximum diameter is selected for convective type (Heymsfield et al., 2013):

$$
D_{\max }=2.1 e^{0.070 T}(\mathrm{~cm})
$$

This article is protected by copyright. All rights reserved. 
Whereas for the stratiform areas in Box 2, Box 3 and Box 5:

$$
D_{\max }=1.1 e^{0.069 T}(\mathrm{~cm})
$$

In the lower part of the distribution $D$ has been limited to $20 \mu \mathrm{m}$. Once the fitted gamma functions $N(D)$ are obtained, photon mean free paths are calculated according to Thomason and Krider (1982):

$$
\Lambda \approx \frac{1}{\int_{D_{\min }}^{D_{\max }} \pi D^{2} N(D) d D}
$$

Finally, the optical depth $\tau$ is calculated according to the corresponding geometric deepness $L$ of the given reflectivity region above the lightning channel:

$$
\tau=\frac{L}{\Lambda}
$$

With the available data and the presented calculations, we cannot provide a precise estimation of the optical depth. From our experience some of the aspects to consider in the future are:

1) Better radar vertical resolution is convenient. Here we cannot resolve levels higher than $10 \mathrm{~km}$ for all the regions of the flash, because the radar has been configured to monitor rain mainly.

2) By increasing the number of elevations or scanning continuous vertical cross sections (like sector range height indicator - RHI) with a polarimetric radar, like this one, polarimetric variables like differential radar reflectivity (ZDR), specific differential phase $\left(\mathrm{K}_{\mathrm{DP}}\right)$ and correlation coefficient among horizontal and vertical polarization can be augmented to estimate the type of ice particles and its size ( Liu and Chandrasekar, 2000);

3) C-band radars detect mostly precipitation size particles. The referenced works allow to extend to lower size particles, even to the few $\mu m$ size. However, we have found that at temperatures lower than $-40^{\circ} \mathrm{C}(\sim 11 \mathrm{~km})$ the density of low 
sized particles increases several orders of magnitude providing very dense clouds that result in an increase of the optical depth by an order of magnitude. A similar unrealistic effect is found by Rutledge et al. (2020) in relation of the temperature dependence of the intercept parameter.

Despite the assumptions and limitations, the relative optical depths presented in Table 1 present a reasonable agreement with the observed luminosity features in each box.

This article is protected by copyright. All rights reserved. 
a)

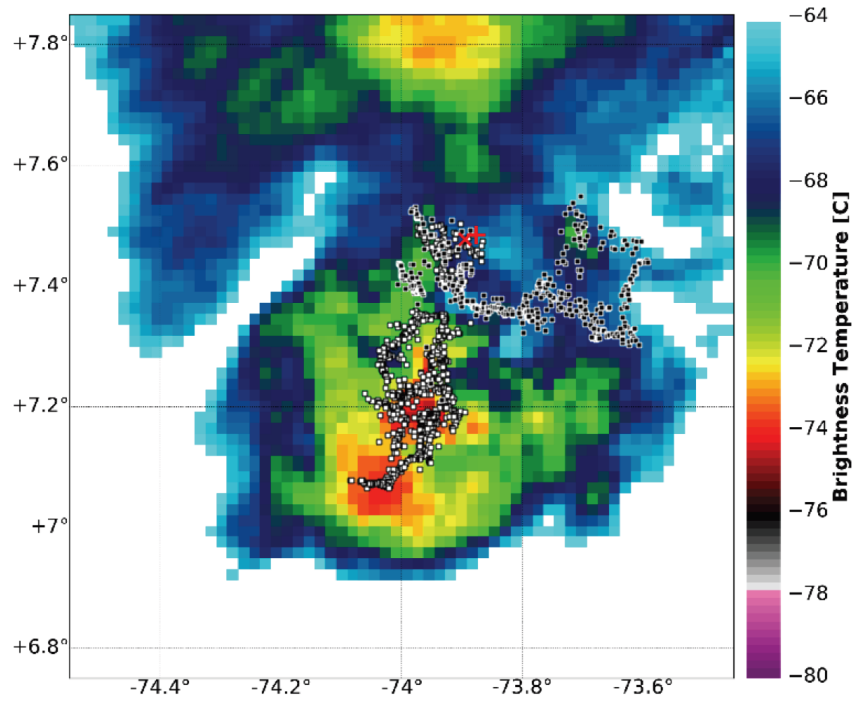

b)

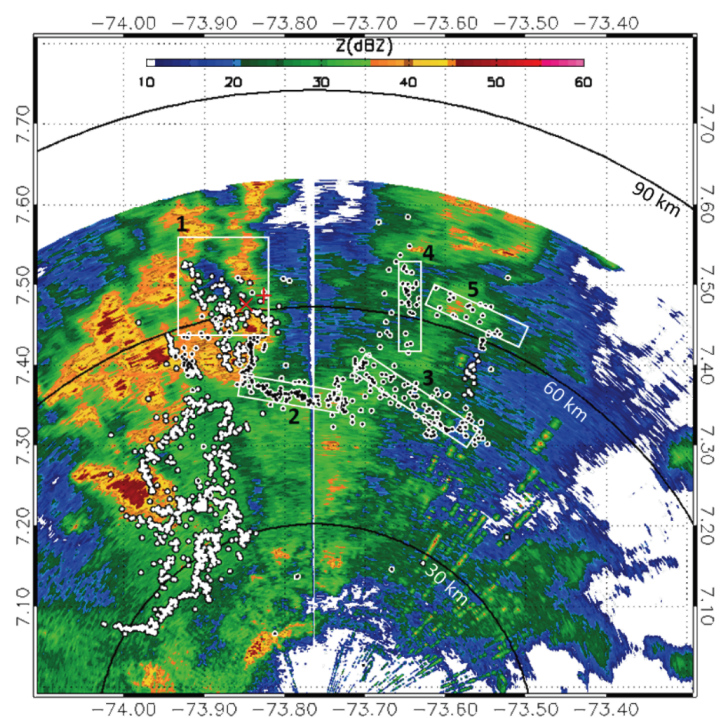

c)

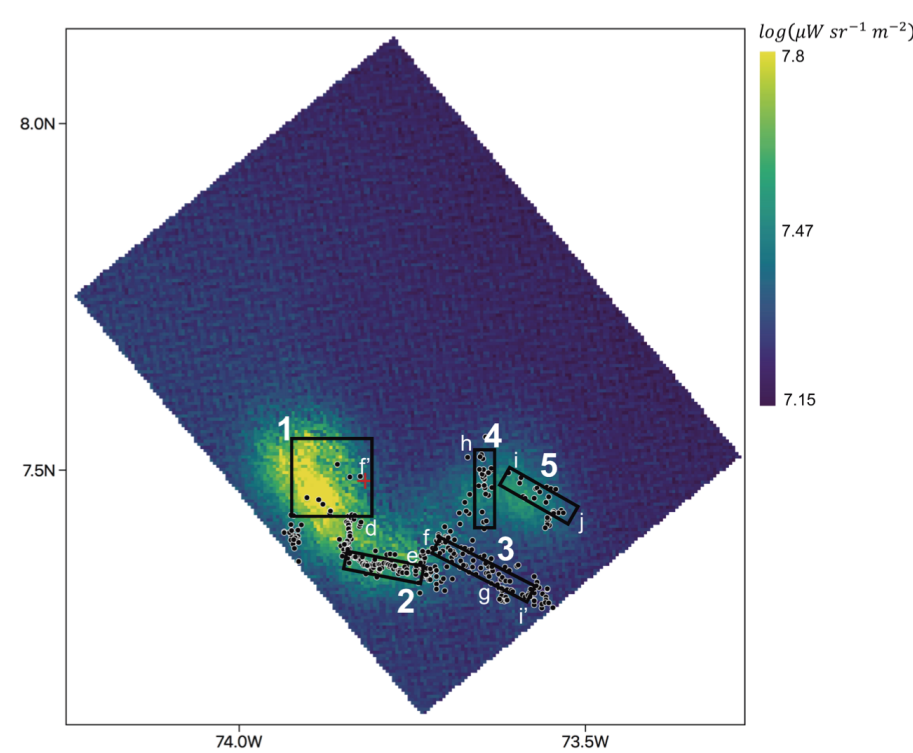

This article is protected by copyright. All rights reserved. 
2018-11-22 8:57:21.336 - 8:57:22.568 UTC
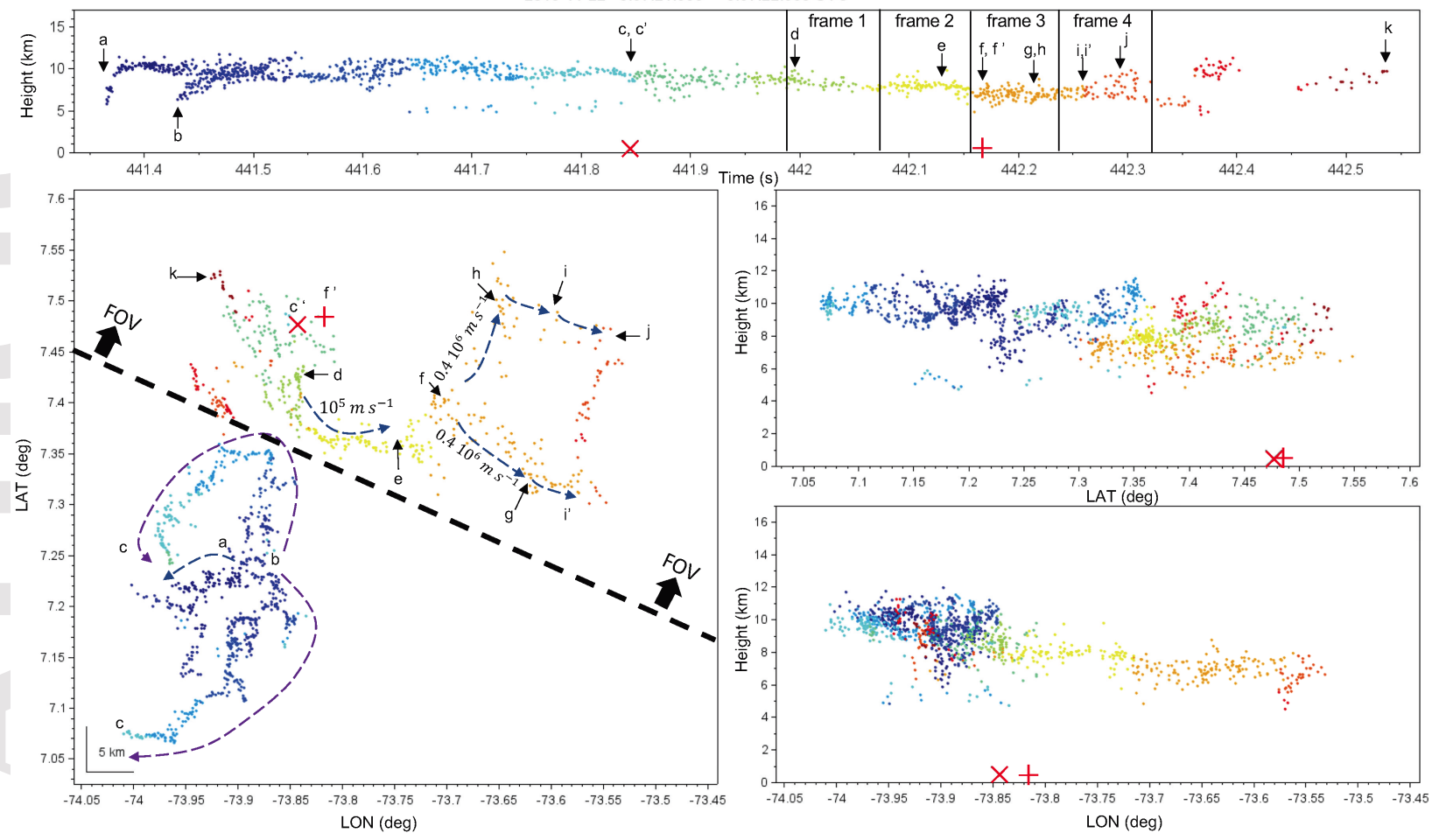

This article is protected by copyright. All rights reserved. 
a)

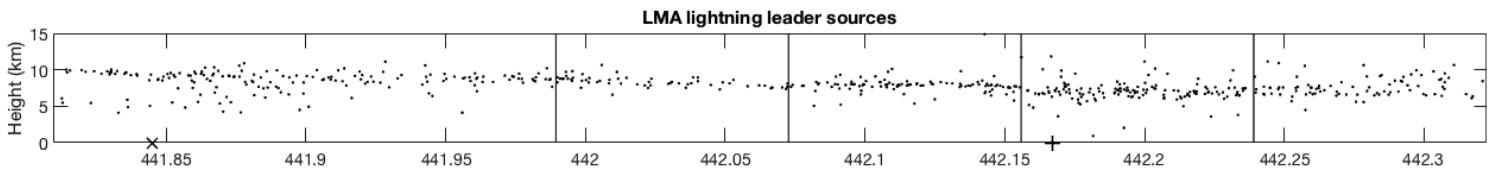

b)

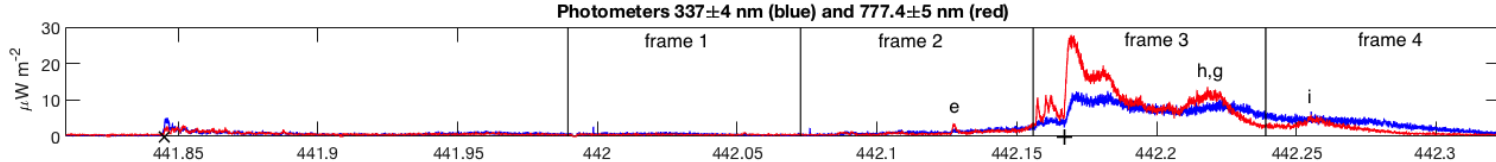

c)

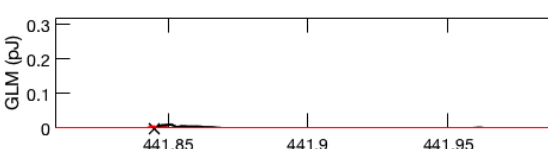

Radiance GLM (black) and LIS (red)
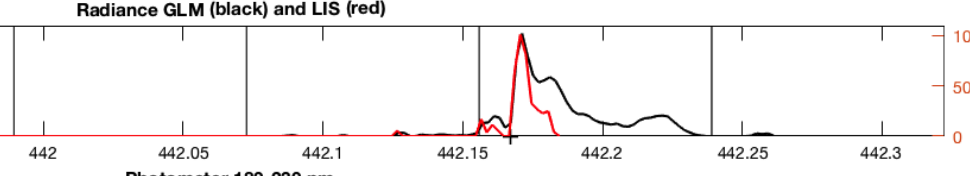

d)

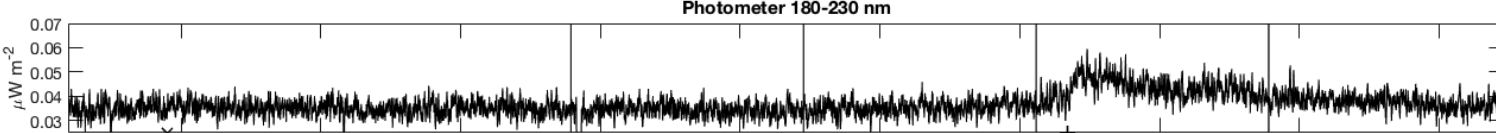

e)

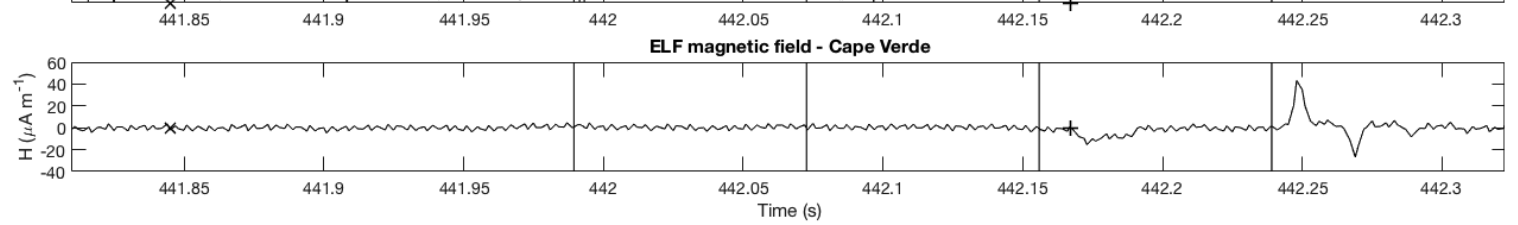

This article is protected by copyright. All rights reserved. 
a)

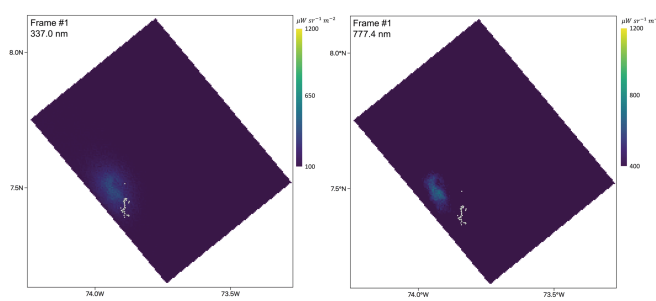

b)
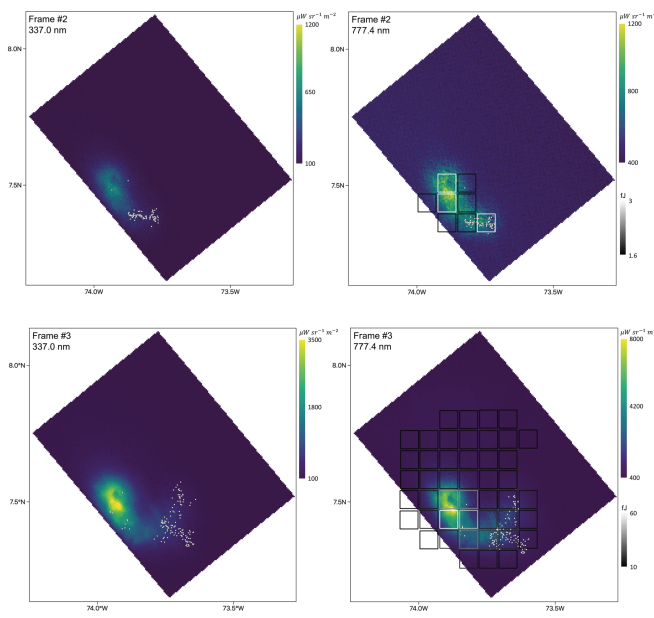

d)

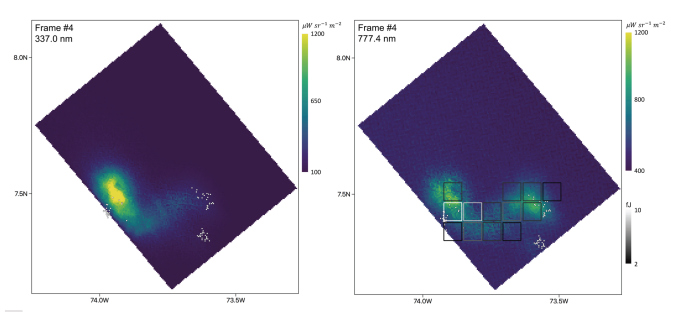

This article is protected by copyright. All rights reserved. 

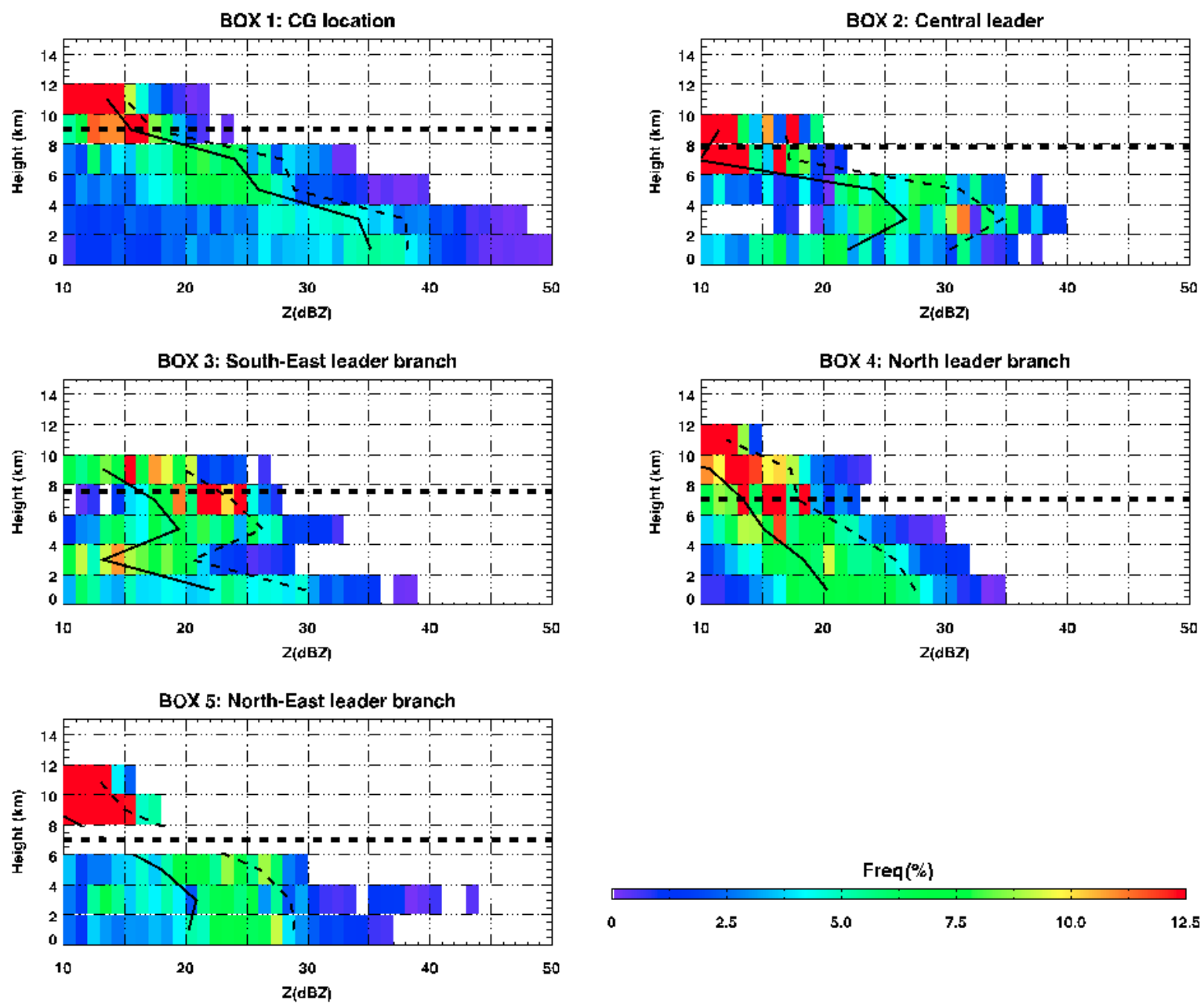

This article is protected by copyright. All rights reserved. 
a)

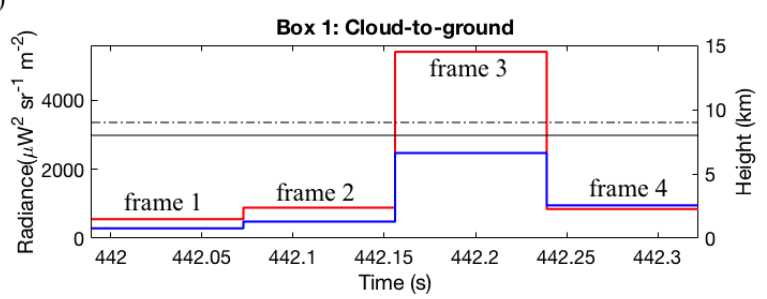

c)

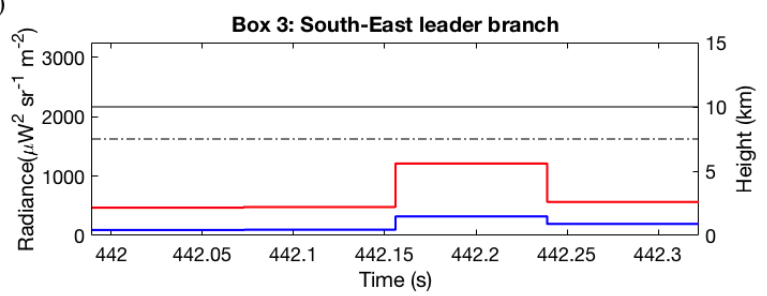

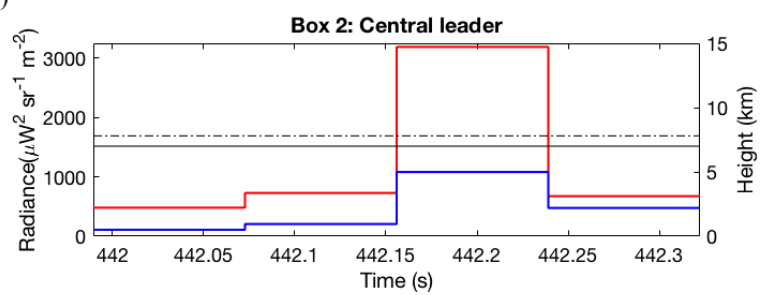

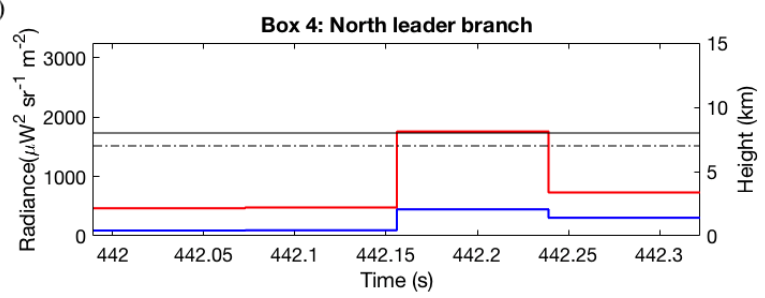

e)

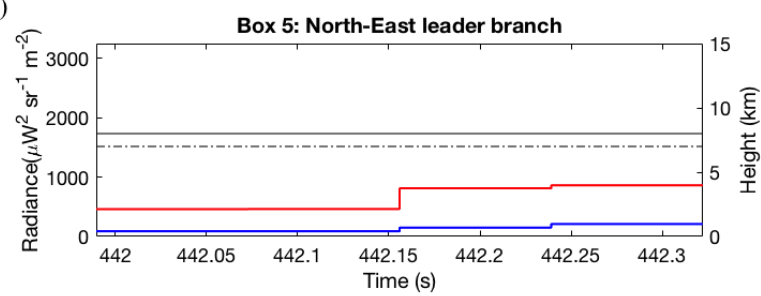

This article is protected by copyright. All rights reserved. 